\title{
ADA APA DALAM "HUTAN MELAYU"? NARATIF FIZIKAL DAN SPIRITUAL HUTAN \\ MELAYU DI ZAMAN BRITISH-MALAYA
}

\section{("What's inside Malay Forests?" Physical and spiritual narrative of the Malay forests in British-Malaya)}

\author{
Puteh Noraihan A. Rahman \\ ann@ukm.edu.my
}

Pusat Pengajian Citra Universiti, Universiti Kebangsaan Malaysia

Terbit dalam talian (published online): 1 Januari 2021

Sila rujuk: Puteh Noraihan A. Rahman. (2021). Ada Apa dalam "Hutan Melayu"? Naratif Fizikal dan Spiritual Hutan Melayu di Zaman British-Malaya. Melayu: Jurnal Antarabangsa Dunia Melayu, 14(1), 1-20.

\begin{abstract}
Abstrak
Menurut WWF, hutan meliputi 30\% permukaan bumi dan merupakan sistem sokongan yang penting dalam menyeimbangi ekosistem dunia (World Wide Fund for Nature (WWF) n.d.). Sebermulanya kehidupan makhluk di alam ini, sumber hutan menjadi nadi kehidupan manusia sejagat. Kebergantungan manusia terhadap hasil hutan bukan sahaja menjadi tunjang keberlangsungan kehidupan sesebuah keluarga yang nukleus tetapi juga turut menyumbang kepada ekonomi masyarakat setempat. Seperti yang diketahui, hutan Malaysia terdiri daripada hutan gunung, hutan hujan tropika, hutan paya serta hutan pantai. Bagi masyarakat Melayu tradisional, kebergantungan terhadap hutan penting bagi kesinambungan kehidupan. Selain berfungsi sebagai sumber makanan, hutan turut menyumbang kepada aspek kebudayaan masyarakat dalam Tamadun Melayu. Oleh yang demikian, kajian ini bakal menganalisis gambaran hutan Melayu berasaskan penulisan pegawai British dan penulis zaman kolonial seperti Maxwell, Clifford, Swettenham, Fauconnier, Endicott, Winstedt, Skeat, Wilkinson serta Annandale. Dengan menggunakan pendekatan naratif dan autoetnografi, pandangan mengenai hutan Melayu dinilai dari perspektif Barat iaitu berdasarkan pengamatan pegawai British-Malaya serta sarjana Barat yang mendalami citra masyarakat Melayu pada zaman itu. Penulisan ini akan memperlihatkan pandangan semesta orang Melayu mengenai hutan mereka dalam bentuk fizikal dan spiritual melalui lensa masyarakat Barat.
\end{abstract}

(C) Dewan Bahasa dan Pustaka. 2021. This work is licensed under the term of the Creative Commons Attribution (CC BY) (http://creative commons.org/licenses/by/4.0/)

ISSN 1675-6460 e-ISSN 2682-8049 
Kata kunci: Hutan Melayu, British-Malaya, British kolonial, sejarah alam sekitar, ketamadunan Melayu

\begin{abstract}
According to the WWF, forests cover $30 \%$ of the earth's surface and act as important support systems in balancing the world ecosystem (World Wide Fund for Nature $(W W F)$ n.d.). They are home to many plant and animal species and a critical sourcefor sustaining human livelihood. Human dependency on forest products is the backbone of not only the survival of a nuclear family but also contributes to the economy of the local community. As known, Malaysian forests consist of mountainous forests, tropical rainforest, swamps and coastal forests. As for traditional Malay society, they relied heavily on forests for survival. Besides its functioning as a source of food, forests also contribute to the cultural aspects of society in the Malay civilisation. Hence, this study will analyse the image and description of the Malay forests based on the writing of British officers and writers during the colonial era such as Maxwell, Clifford, Swettenham, Fauconnier, Endicott, Winstedt, Skeat, Wilkinson and Annandale. By using a narrative approach and auto-ethnography, views of the Malay forest will be assessed from Western perspectives, which are based predominantly on the observations of British-Malaya colonial officers and Western scholars involved directly in the Malay community and their communal activities at the time. In summary, this writing will depict the worldview of the Malays about their forests, physically and spiritually, through the lens of Westerners.
\end{abstract}

Keywords: Malay Forests, British-Malaya, British colonial, environmental history, Malay civilization

"These Malays are interesting. So is the jungle. Tree, nothing but trees. A monotorious country. One enters it---I feel I am nearly asleep---and finds the enchanted forest

(Henri Fauconnier, 1965: 90)

\title{
PENDAHULUAN
}

Hutan yang wujud sejak beratus juta tahun dahulu merupakan nadi kepada keberlangsungan hidupan makhluk di muka bumi. Menurut Nigh dan Nations (1980: 12), lebih seratus juta yang lalu, hutan tropika memainkan peranan dalam evolusi daratan seperti tumbuhan dan haiwan. Hutan tropika juga memelihara pelbagai spesies hidupan sejak zaman purba dan menjadi inovasi bidang sains biologi untuk 
menghasilkan spesies baharu. Terdapat tamadun lama yang berkembang di kawasan pendalaman seperti, tamadun Angkor Wat di Kemboja dan juga tamadun Maya, iaitu salah satu tamadun Meso-Amerika. Kedua-dua tamadun ini berkembang di kawasan pendalaman hasil kejayaan penciptaan dan inovasi daripada hasil hutan. Juga, kewujudan tamadun-tamadun awal di kawasan hutan dan pergunungan menunjukkan bahawa lokasi pedalaman tidak membantutkan perkembangan sesebuah tamadun. Lokasi yang jauh dari persisiran pantai membantu masyarakat kawasan pendalaman berfikiran kreatif dan kritis untuk menggunakan kemahiran masing-masing bagi penciptaan alatan sains dan teknologi terutamanya dalam sistem jaringan pengangkutan bagi memudahkan pergerakan masyarakat tamadun awal dari suatu tempat ke tempat yang lain. Perkara ini selari dengan pendirian Nigh dan Nations (1980) mengenai kemahiran individu yang tinggi dalam kelompok masyarakat serta populasi penduduk Maya dan Angkor Wat yang menyumbang kepada budaya hutan tropika.

Dalam kajian ini, hutan Melayu dijadikan subjek kajian kerana menyimpan 1001 misteri yang wajar dirungkaikan. Didapati kurang kajian dibuat terhadap budaya yang melibatkan hutan Melayu apatah lagi semasa zaman penjajahan British di Tanah Melayu sekitar abad ke-19 hingga 20. Terdapat pelbagai elemen budaya yang dapat diketahui melalui sumber naratif pegawai British Malaya dan juga penulis Barat yang lain. Penempatan pegawai kolonial di Malaya menyumbang secara tidak langsung kepada sejarah Malaysia melalui penulisan temtamg etnografi masyarakat Melayu oleh pegawai British. Perlu diketahui juga, penulisan mereka tidak mungkin berjaya jika tiada kerjasama dengan penduduk tempatan. Pakri (2011) menjelaskan, sikap masyarakat Melayu yang terbuka, mudah menerima dan gemar mengambil tahu banyak membantu pentadbiran British. Kerjasama yang erat antara orang Melayu dengan British terutamanya dari segi ekonomi dan sosiobudaya sedikit sebanyak merobah cara pemikiran orang Melayu. Hal ini termasuklah yang berkaitan dengan adat dan kepercayaan lama yang mengandungi unsur khurafat dan tahyul.

Berbalik kepada ciri fizikal hutan Melayu yang memukau, pegawai British kebanyakannya menulis tentang perkara ini. Keindahan hutan Melayu dinukilkan oleh Sir Hugh Charles Clifford dalam bukunya yang bertajuk, In Court and Kampung, menampakkan kekaguman beliau akan hutan Melayu:

These forests are among the wonderful things of the Earth. They are immense in extent, and the trees which form them grow so close together that they tread on one another's toes. All are lashed, bound and relashed into one huge magnifiecient tangled net by the thickest underwood and the most marvellous parasitic growths that nature has ever devised. No human being can force his way through his maze 
of trees, shrubs, thorns, plants and creepers; even the great beasts which dwell in the jungle find their strength unequal to the task and have to follow game paths, beaten out by the passage of innumerable animals, through the thickest and deepest parts of the forest. The branches cross and recross, bound together by countless creepers, forming a green canopy overhead through which the fierce sunlight only forces a partial passage, the struggling rays flecking the trees on which they fall with little splashes of light and colour. The air 'hangs heavy as remembered sin', and the gloom of a great cathedral is on every side. Everything is damp, moist and oppresive. The soil and the cool dead leaves under foot are dank with decay and sodden to the touch. Enormous fungus growths flourish luxuriantly; and over all, during the long hot hours of the day, hangs a silence as of the grave. Though these jungles teem with life, no living thing is to be seen save the busy ants, a few brilliantly coloured butterflies and insects, and an occasional nest of bees high up in the tree-tops. A little stream ripples its way over the pebblesof its bed and makes a humming murmur in the distance; a faint breeze, sweeping over the forest, gently sways the upper branches of a few of the tallest trees, but, for the rest, all is melancholy, silent and motionless

(Clifford 1989, 5)

Dalam manuskrip Malay Forest, karangan George Maxwell turut menyentuh tentang keindahan hutan Melayu. Ketakjuban Maxwell terhadap hutan melalui dinukilkan dengan penuh puitis melalui bait seperti, "Then you see that the whole cloud is swimming on into the mountain." (Maxwell, 1982: 4). Selain itu, Maxwell turut memberikan gambaran geografi hutan hujan tropika Melayu secara terperinci. Daripada penulisan Maxwell, ditemui tentang kebergantungan masyarakat Melayu terhadap hutan untuk penempatan dan juga kegiatan pertanian. Perkampungan Melayu terletak berhampiran hutan. "In a Malay village one may better realise the manner in which forest hems in the cultivated area. The settlement is generally situated on the banks of a river" (Maxwell, 1907: 2). Maxwell turut menjelaskan pola penempatan orang Melayu, iaitu kawasan sawah padi yang dikelilingi belukar. Sesudah belukar, ditemui hutan tebal, seterusnya kawasan pergunungan sehinggalah penghujungnya bertemu dengan tebing laut atau pesisiran pantai (Maxwell, 1907: 3).

\section{PENDEKATAN AUTOETNOGRAFI DAN NARATIF}

Kaedah autoetnografi digunakan untuk menganalisis pengalaman pegawai British dan sarjana Barat yang menulis tentang hutan Melayu. Kaedah ini sesuai kerana autoetnografi merupakan cara untuk menganalisis dan menerangkan data secara 
sistematik melalui pengalaman penulis tentang citra sesuatu masyarakat. Pendekatan ini dipopularkan oleh Douglas dan Carless (2013). Jones (2005) mengatakan bahawa autoetnografi ialah penceritaan tentang pengalaman seseorang mengenai sesuatu peristiwa, gabungan kehidupan dan kesenian, teori, imaginasi dengan bertujuan untuk menyampaikan pengalaman mereka kepada pembaca agar pengalaman tersebut dapat dirasai bersama. Pendekatan naratif yang digabungkan bersama-sama dengan pendekatan autoetnografi adalah wajar, dan diterapkan dalam kajian ini bagi memperlihatkan pandangan semesta sesuatu masyarakat. Pendekatan naratif adalah baik bagi penceritaan sejarah. Menurut Tamura (2011), penyampaian bahan sejarah secara naratif, dapat meningkatkan kefahaman pembaca seperti penceritaan mengenai sesuatu peristiwa dan perihal diri manusia. Penulis bersetuju dengan Roberts (2006), Tamura (2011: 150) yang menyimpulkan bahawa sejarah dilabelkan sebagai disiplin yang bersifat ideografik, iaitu penelitian secara mendalam terhadap suatu peristiwa sejarah yang dikaji. Pendekatan ini berlawanan dengan disiplin ideografik, iaitu disiplin nomometik, yang lebih bersifat abstrak dan lebih cenderung menentukan hukum kepada sesuatu peristiwa (generalisasi) berdasarkan trend, paten serta faktor yang mempengaruhi sesuatu fenomena. Ahli sosiologi sangat mementingkan penggunaan teori sosial dan keadaan ini memisahkan mereka dengan ahli sejarah. Namun begitu, menurut Tamura (2011), ahli antropologi sosial seperti Geertz dan Sahlins mula menggabungkan kaedah antropologi dengan sejarah dan garis pemisah akibat disiplin yang berbeza sejak 50 tahun lalu berakhir setelah kemunculan disiplin baharu yang dipelopori oleh Foucault, Bakhtin, Bourdieu serta beberapa ahli falsafah lain (Tamura, 2011: 150-157). Oleh yang demikian, kemantapan kajian ini diperlihatkan melalui hasil gabungan autoetnografi dan juga kaedah naratif untuk menganalisis penceritaan hutan Melayu oleh pegawai dan sarjana Barat.

\section{HUTAN MELAYU}

Seperti yang diketahui, "hutan Melayu" ialah gabungan antara dua perkataan, iaitu hutan dan Melayu. Untuk menjelaskan fungsi sintaksis "hutan Melayu", secara teknikalnya hutan merupakan objek dan subjeknya ialah orang Melayu. Berlatarkan masa dan tempat zaman kolonial British sekitar kurun ke-19 hingga ke-20, penilaian tentang pandangan semesta tamadun Melayu turut membangkitkan beberapa persoalan, antaranya termasuklah:

(i) Bagaimanakah pandangan masyarakat Melayu terhadap hutan?

(ii) Sejauh manakah hutan mempengaruhi kehidupan masyarakat Melayu?

(iii) Apakah budaya yang terbentuk daripada hutan Melayu? 
Bagi pendefinisian "hutan Melayu", terminologi hutan ini dikhaskan kepada komuniti Melayu kerana penceritaan mereka berkisar kepada orang Melayu dan tidak kepada orang asli serta kaum-kaum lain yang mendiami Tanah Melayu pada masa itu. Analisis kajian juga mendapati terdapat penceritaan tentang masyarakat bukan Melayu dalam penulisan mereka tetapi bagi subjek hutan Melayu, perbincangan tertumpu pada orang Melayu secara khusus. Mungkin disebabkan orang Melayu merupakan kaum terawal yang mendiami dan memerintah Malaya seperti yang dijelaskan oleh Cameron (1865: 124); "The Malays are entitled to be looked upon as the first rulers and the present people of Singapore and Malay Peninsula."

Terminologi "hutan Melayu" itu sendiri diungkapkan oleh pegawai British, Maxwell sebagai Malay Forests. Pada penghujung abad ke-19, semasa penjajahan British, orang-orang di Tanah Melayu mengamalkan sistem feudal yang diwarisi

sejak dari zaman dahulu. Secara teknikal, Raja Melayu memiliki tanah jajahannya sendiri. Kenyataan ini disokong oleh Clifford (1989: 1):

In 1874, when British Government first interfered in the administration of the Malay States of the East Coast of Peninsula Malaya, each state was ruled by its own Sultan or Raja... The Raja was, of course, the paramount authority and all power emanated from him. Technically, the whole country was his property, and all its inhabitants his slaves. Each State was divided into districts which were held in fief by the Orang Besar, of Great Chiefs.

\section{DESKRIPSI FIZIKAL HUTAN MELAYU}

\section{Permukaan hutan Melayu}

Hutan Melayu dapat dikategorikan sebagai hutan primer, iaitu hutan yang tidak terusik oleh kegiatan manusia. Melalui pemerhatian Cameron (1865), hutan Melayu yang digambarkan menepati ciri-ciri hutan primer. Cameron yang berasal dari England menyifatkan hutan Melayu agak asing dan sukar diklasifikasikan kerana belum pernah beliau temui hutan sedemikian. Memetik pernyataan Cameron (1865: 85), “... it is difficult to convey any adequate idea of the jungle to those accustomed to the forests of the tempees (sic.) and another rate zones."

Bagi Cameron, tumbuh-tumbuhan dalam hutan Melayu amat menyumbang dari sudut ekonomi mahupun budaya orang Melayu. Orang Melayu menggunakan tumbuhan hasil hutan bukan sahaja sebagai sumber makanan tetapi juga dijadikan barang perhiasan seperti ukiran kayu" (Cameron, 1865: 50). 
To begin with there are the trees of all sizes, from the smallest shoot to the giants of the jungle, towering to a height of 150 feet.

Dari sudut geografi pula, permukaan hutan Melayu terdiri daripada tanah rendah, tanah tinggi, hutan paya bakau dan paya air tawar. Menurut Kaur dan Metcalfe (1999), kawasan bertanah rendah yang ditumbuhi pokok renek akan sentiasa bersaing untuk meneruskan kelangsungan hidup kerana cahaya matahari tidak dapat menembusi lapisan kanopi pokok yang tinggi dan seterusnya tidak sampai ke lantai hutan (Kaur \& Metcalfe, 1999: 46). Cameron (1865) pula menjelaskan bahawa kawasan pendalaman Singapura mempunyai pohon yang besar. Pohon-pohon ini tumbuh berdekatan, seperti bertangkai dan berjuntai serta batangnya berdiameter antara dua hingga enam kaki. Pepohon yang rapat seperti payung kanopi ini membuatkan lantai hutan gelap serta pohon renek yang tumbuh di lantai hutan terbantut tumbesarannya. Antara pohon liar yang buahnya boleh dimakan ialah manggis, durian, mangga, buah nangka dan jambu (Cameron, 1865: 85). Selain itu, permukaan hutan Melayu dapat dilihat dalam catatan Sir Frank Swettenham yang menyifatkan hutan Melayu kaya

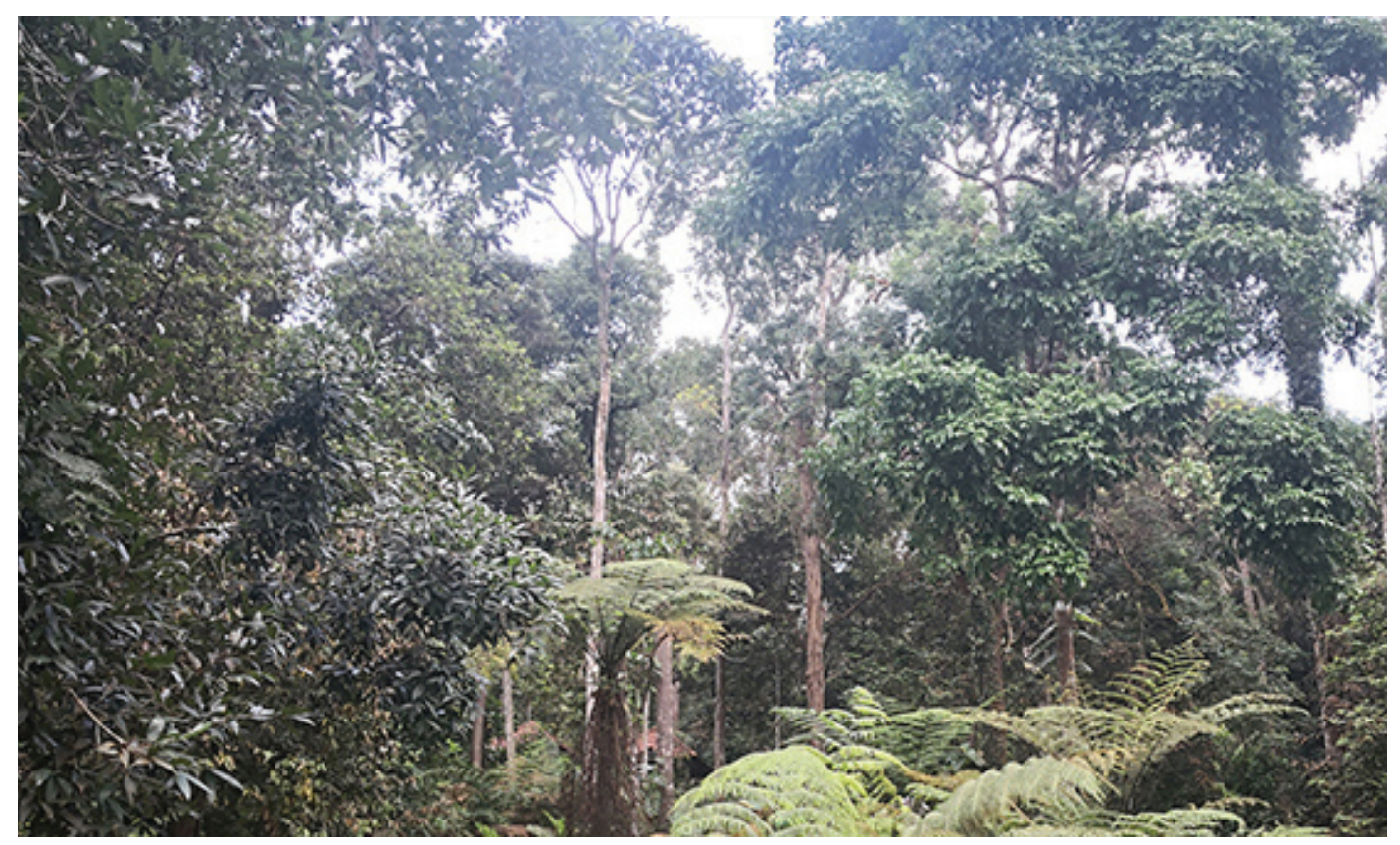

Rajah 1 Hutan hujan Khatulistiwa di Malaysia (hutan Melayu). 
dengan alam semula jadi. Pengamatan beliau terhadap hutan tropika Melayu sangat menarik. Swettenham (2003: 44) menjelaskan, "Mula-mula sekali, terdapat sungguh banyak pokok-pokok dari berbagai-bagai peringkat kecil dan besar seperti raksasa di hutan mencapai sehingga 150 kaki."

Menurut beliau lagi, selain saiz pokok yang berbeza, cirinya juga berlainan seperti yang menjalar, berduri, paku-pakis, tutup bumi serta lalang. Perkara yang menarik mengenai hutan Melayu ialah peristiwa orang sesat dan hilang di hutan. Keadaan fizikal hutan yang gelap, denai yang ditutupi pohon renek di lantai hutan secara tidak langsung mudah mengakibatkan seseorang tersesat jalan dan boleh mengundang maut sekiranya terperangkap di dalam hutan dalam jangka waktu yang lama. Terdapat peringatan daripada Swettenham (2003) tentang denai dalam hutan Melayu iaitu:

Meredah masuk ke tempat seperti itu memang mustahil, kalau merangkak pun tidak boleh ditembusi, hanyalah satu cara sahaja, iaitu dengan mencantas dan memotong untuk membuat lorong. Tiada siapa yang cuba-cuba berjalan melalui hutan dara melainkan jika ia memburu binatang atau ada alat khas dan cara tertentu untuk membuat laluan.”

(Swettenham 2003: 44)

Swettenham juga menjelaskan tentang elemen permukaan hutan yang lain seperti sungai dan juga keadaan dalam hutan semasa perubahan waktu. Swettenham menceritakan kepayahan untuk menelusuri sungai dalam hutan Melayu disebabkan gumpalan dahan dan ranting yang tebal menyebabkan sukar untuk memasuki sungai di dalam hutan tebal Melayu. Tatkala matahari sudah tiada, Swettenham (2003) menjelaskan deria penglihatan manusia seakan-akan tidak berfungsi.

Sebaik sahaja matahari terbenam, kegelapan menyelubungi apa-apa sahaja di dalam hutan itu, dan kegelapan itu begitu pekat sehingga kalau kita memandang dengan mata terbuka luas pun, kita rasa seolah-olah seperti buta. Mereka yang begitu malang yang terpaksa bermalam di hutan ini tanpa obor atau lampu, mengetahui bahawa tidak ada apa yang boleh dibuat melainkan duduk sahaja menunggu hari siang.

(Swettenham, 2003: 47)

Menurut Maxwell, pohon yang berhampiran dengan seseorang yang berdiri di luar hutan berwarna kehijauan dan jika pandangan disorot jauh ke dalam hutan menampakkan warna kehitaman akibat kegelapan. Terdapat pergunungan dan 
gaung-gaung di lerengnya. Sesekali kelihatan lombong bijih timah antara dua buah bukit memperlihatkan seolah-olah sebuah pulau di tengah-tengah lautan. Ketinggian puncak gunung mencecah 5000 kaki (Maxwell, 1982: 3-4)

\section{Binatang}

Terdapat beberapa haiwan dalam hutan dianggap keramat. Maksud keramat ialah suci dan berkat kesuciannya dapat melakukan sesuatu yang ajaib atau tempat atau sesuatu yang dianggap suci. Keramat bukan sahaja untuk manusia (Pusat Rujukan Persuratan Melayu n.d.). Berdasarkan catatan Maxwell, terdapat beberapa haiwan dianggap keramat (kramat) di Lembah Kinta antaranya termasuklah badak sumbu, harimau dan gajah. Maxwell menceritakan kisah tentang penduduk kampung cuba membunuh badak sumbu keramat, namun untuk menembusi badan haiwan tersebut dengan peluru menemui kegagalan. Kelebihan setiap badak sumbu dilihat pada sumbunya. Selain saiz sumbunya yang panjang dan besar, keistimewaannya juga terpancar daripada warna sumbu seperti berwarna biru kerana badak jenis ini hampir pupus. Terdapat beberapa jenis sumbu badak, iaitu sumbu lilin (wax-colored horn), sumbu api (flamed-colored horn), sumbu nila (blue horn) dan akhir sekali sumbu itam (black horn) (Maxwell, 1982: 10-11). Wujud juga kisah yang sama tentang gajah keramat dan haiwan-haiwan lain yang berupaya menyerupai pasukan pemburu.

The attendant spirit of kramat animal has power to deceive the hunter by altering the appearance of the hunted animal or by giving its shape to one of the hunters or their attendants, and on one occasion a gallant officer in the N-Regiment fell its victim.

(Maxwell, 1982: 12)

Selain membuat laluan ataupun denai untuk menelusuri hutan belantara Melayu, antara perkara lain yang perlu diketahui ialah serangga yang menghuni lantai hutan. Terdapat pelbagai jenis hidupan dalam hutan Melayu walaupun kecil tetapi perlu diberikan perhatian. Iklim Malaya yang panas dan lembap sepanjang tahun menggalakkan pembiakan serangga dan haiwan yang menjalar di lantai hutan. Swettenham berpendapat, serangga dalam hutan Melayu amat menjengkelkan kerana walaupun kecil tetapi berbisa. Menurut Swettenham (2003):

... setiap gumpalan tumbuh-tumbuhan ini ada tersorok berbagai-bagai jenis serangga yang tidak menyenangkan, yang merayap, yang melompat, juga banyaknya pacat yang merayap menembusi stokin dan baju melainkan jika yang tenunannya rapat, 
dan juga segala jenis siput, lipan, kala jengking, tebuan, lalat menyengat, ulat bulu yang kalau terbenam bulunya dalam kulit kita, sungguh gatal tidak terhingga, ular, yang bisa dan tidak, semut yang menggigit seolah-olah hendak membunuh, dan akhir sekali, tetapi tidak kurang bahayanya ialah nyamuk, bila terjumpa dengan manusia, tidak langsung melepaskan peluang.

(Swettenham, 2003: 45)

Maxwell (1982) menambah, terdapatbeberapa serangga di lantai hutan yang terpaksa dihadapi oleh individu yang memasuki hutan. Antaranya termasuklah ulat gonggok, kala jengking, penyengat, dan serangga terbang dan ular berbisa. Bagi Swettenham, tiada orang yang suka memasuki hutan Melayu jika tidak bersebab. Kebanyakan mereka yang masuk ke hutan untuk bersukan atau berburu (Maxwell, 1982: 43).

Secara geografi, dapat disimpulkan bahawa hutan Melayu terdiri daripada tiga bahagian. Pertama sekali bahagian permukaan atas yang disebut sebagai lapisan kanopi kerana dahan dan dedaun meliputi bahagian atas dan membentuk seakan-akan payung dan sedikit sebanyak menghalang cahaya matahari menembusi ruang hutan. Kedua, ruang antara lantai hutan dengan kanopi hutan. Lapisan terakhir ialah lantai hutan. Menurut Kaur dan Metcalfe (1999), lapisan hutan dihuni oleh pelbagai jenis haiwan dan juga pokok spesies berbeza seperti bangunan yang bertingkat. Terdapat

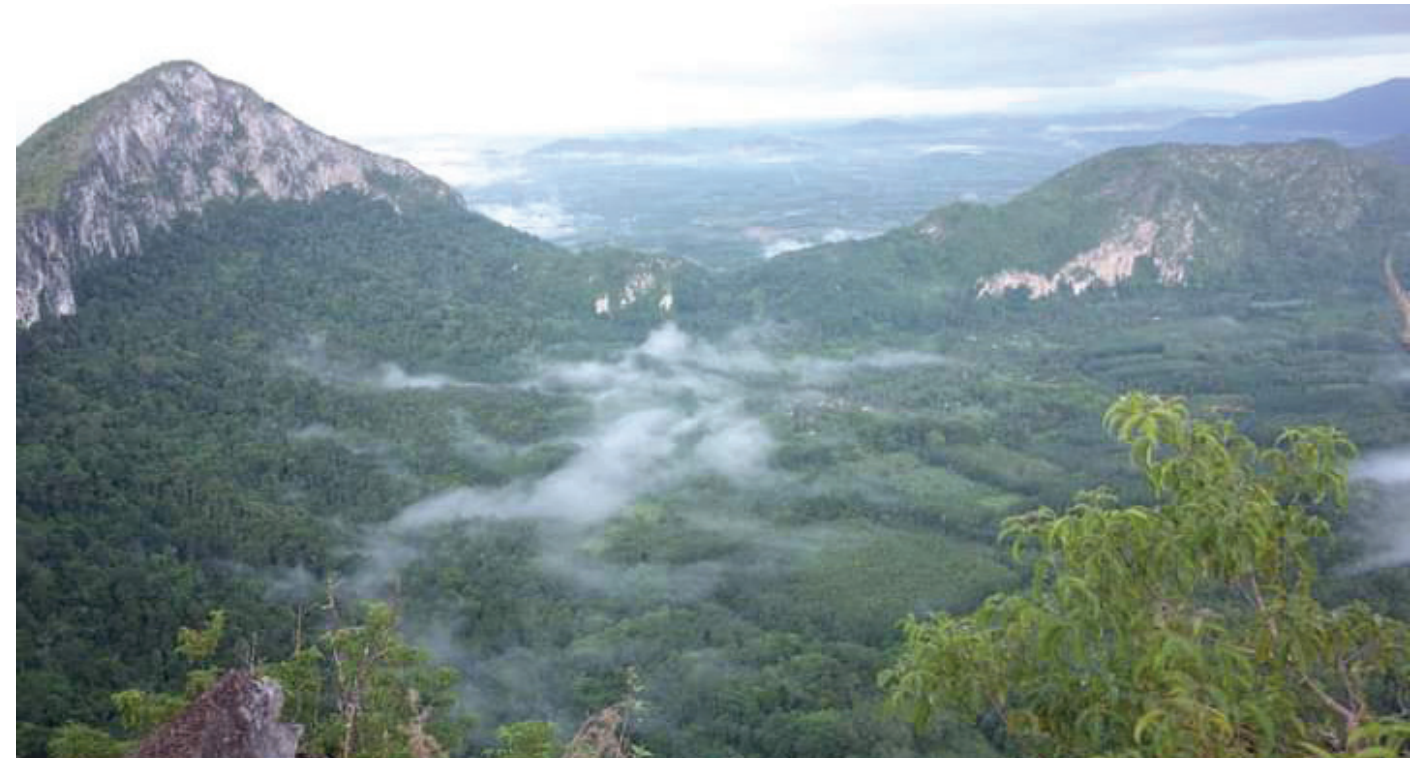

Rajah 2 Kehijauan lapisan kanopi hutan Melayu yang memukau di Gunung Baling, Kedah. (Sumber: Foto sumbangan Dr. Suhaimi Isa) 
hidupan hutan Melayu yang boleh menghuni pada semua peringkat atau ruang hutan, namun mereka akan tinggal di kawasan yang selesa dihuni demi kemandirian masing-masing. Menurut Kaur dan Metcalfe (1999), peringkat paling atas, iaitu kanopi hutan dihuni oleh spesies burung dan mamalia yang memakan buah-buahan dan daun-daunan. Spesies ini jarang turun ke lapisan bawah. Mamalia yang tinggal di lapisan atas kanopi bergayut dan berhayun dari dahan ke dahan. Antara haiwan yang menggelongsor dari pokok ke pokok ialah tupai terbang dan lemur (sejenis kera) yang dapat terbang sejauh 100 meter. Selain itu, beberapa spesies haiwan lain yang aneh seperti katak terbang dan ular yang juga menggelongsor dari dahan ke dahan. Terdapat juga spesies haiwan yang jarang dijumpai seperti kongkang (loris), siamang (gibbon), monyet (langur) dan orang utan terdapat dalam hutan Melayu. Spesies burung yang unik seperti enggang (hornbill) (Kaur \& Metcalfe, 1999: 57). Habitat kepelbagaian spesies monyet dalam hutan Melayu juga turut disokong oleh Cameron (1865). Kebanyakan haiwan yang menghuni hutan ialah monyet, yang terdiri daripada pelbagai spesies dan saiz serta mudah untuk dijinakkan (Cameron, 1865: 88). Melalui pemerhatian Cameron, monyet merupakan binatang yang mudah dijinakkan dan banyak pula jumlahnya. Dengan sumber monyet yang banyak di hutan, orang Melayu dahulu kala banyak menjinakkan monyet bagi kegunaan perladangan seperti memetik buah kelapa. Selain monyet, terdapat babi hutan (wild hogs). Menurut Cameron (1865) lagi, babi hutan membiak di kawasan hutan yang berpaya dan berlumpur. Seperti spesies babi hutan yang lain, badan babi hutan berbulu, berwarna hitam dan bersaiz agak kecil. Haiwan yang paling digeruni ialah harimau. Menurut Cameron, berdasarkan penceritaan orang kampung, harimau tidak menyerang orang jika tidak berasa diancam. Cameron (1865) menjelaskan:

\begin{abstract}
I believe that face to face a tiger will not attack a human being, unless he displays a thorough want of nerve; the Malays are also of this opinion, but express it differently. They say that, "if you will only speak to a tiger, and tell it that it can get plenty of food in the jungle beside you, the animal will be persuaded and leave you unmolested." Unfortunately, few get the chance to speak to the tigers in this way, because as I have stated, they almost invariably steal up behind those they intend to attack.
\end{abstract}

(Cameron, 1865: 99)

Namun begitu, pernyataan di atas hanyalah teori yang boleh digunakan oleh sesetengah orang dan juga sesetengah tempat kerana di wilayah Wellesley terdapat kes harimau menyerang dan membunuh beberapa orang.

Terdapat binatang unik yang disebut oleh penulis Barat, iaitu tapir. Henri Fauconnier (1990) telah menjelaskan bentuk tapir yang menghampiri rumah 
banglonya. Baginya, tapir kelihatan seperti seekor makhluk yang pelik. "Strange shapes became visible between the trees--the swaying trunk of an elephant, a motionless head with staring eyes". Akhir sekali ialah ungka, iaitu sejenis spesies monyet. Pegawai British memangggil ungka dengan gelaran wah-wah. Menurut Swettenham (1899), "Terdapat beberapa ungka berkumpul di dalam hutan dan di pohon tinggi terutamanya pada waktu pagi. Ungka selalunya berwarna hitam atau berwarna kekuningan. Selain mempunyai lengan dan kaki yang panjang dan kuat, wajahnya kelihatan sedih dan kadang-kadang berubah menjadi marah apabila bergaduh (Swettenham, 1899: 88-89). Swettenham juga menceritakan tentang binatang lain seperti beberapa jenis burung, reptilia, serangga serta mamalia, seladang, badak sumbu, gajah dan harimau (Swettenham, 1899: 163-164). Dapatlah disimpulkan bahawa hutan Melayu ialah habitat yang sempurna bagi kemandirian spesies hidupan jenis tropika kerana taburan hujan yang tinggi serta beriklim panas dan lembap sepanjang tahun.

\section{Spiritualisme Hutan Melayu}

Sebelum spiritualisme hutan Melayu dianalisis dengan lanjut, terdapat beberapa elemen yang berkaitan dengannya perlu ditelusuri. Pertama, konsep demonologi. Menurut Fuad (2018), demonologi ialah kepercayaan terhadap sesuatu yang bukan manusia dan juga bukan Tuhan tetapi bersifat transendental. Secara asasnya, demonologi boleh dikatakan salah satu kepercayaan manusia terhadap makhluk ghaib seperti jin, syaitan, roh dan semangat. Perlu difahami bahawa walaupun satu daripada ciri masyarakat yang bertamadun ialah beragama dan mempercayai tuhan, namun dalam perkara melibatkan demonologi, terdapat kelompok manusia yang turut mempercayai perkara ghaib kerana berada dalam ikatan sosial masyarakat yang sama. Hujah ini turut disokong oleh Grimal (1965) tentang peranan demonologi dalam kehidupan manusia sejagat. Grimal (1965: 412) menegaskan bahawa tema demonologi perlu diasingkan dengan keagamaan. Berdasarkan sumber sejarah dan etnografi, aspek kepercayaan terhadap demonologi ini wujud dan memberikan kesan yang besar dalam psikologi dan sosial masyarakat setempat.

Terdahulu, elemen spiritualisme hutan juga dipengaruhi oleh kepercayaan paganisme. Menurut sejarah orang Celtic (Britain dan Ireland lama) amalan pagan, iaitu menyembah objek yang berasaskan kejadian alam semula jadi tidak langsung menekankan kepercayaan dan kepentingan spiritual hutan (Grimal, 1965).

Kepercayaan mistik dan magik mungkin berpunca daripada tantrisme Buddhisme yang berakar umbi dalam budaya Melayu. Menurut Endicott (1970), kepercayaan Melayu dipengaruhi oleh sistem politik Kerajaan Srivijaya (680M), juga Siam (13M) 
dan juga pemerintahan Majapahit dari Jawa (sehingga kurun ke-14M) (Endicott, 1970: 3-4). Unsur yang menggabungkan tantrisme dan paganisme ini melahirkan ritual tantrik dalam masyarakat Melayu sebelum Islam. Menurut Swettenham (1887), orang Melayu beragama pagan sebelum tahun 1250 dan ada yang mengamalkan agama Hindu sebelum Sultan Mahmud Shah memeluk agama Islam pada kurun ke-13.

Berbalik kepada kepercayaan lama Melayu, pemujaan kepada roh serta semangat nenek moyang serta objek alam semula jadi menjadikan budaya Melayu lama sesuatu yang unik. Seperti yang dijelaskan oleh Puteh Noraihan (2018) mengenai animisme sebelum kedatangan agama Hindu-Buddha di alam Melayu, "Disebabkan itu, sebelum kedatangan agama Hindu dan Buddha, masyarakat Melayu memuja benda yang tidak bernyawa atau lebih dikenali sebagai animisme (Puteh Noraihan, 2018: 15). Skeat (1900: 53) turut menyatakan mengenai Malay Animism yang menyatakan beberapa kisah manusia boleh bertukar menjadi haiwan lain seperti burung, reptilia dan pokok dan proses ini dipanggil sebagai antromorfik. Winstedt (1951) dalam bukunya, Malay Magician pernah menjelaskan tentang kepercayaan kepada roh dan semangat oleh masyarakat Melayu. Winstedt berkata:

What has been written of every Dravidian village is true of every Malay village. It is believed to be surrounded by evil spirits, who are always on the watch to inflict diseases and misfortunes... They lurked everywhere, on the tops of palmyra trees, in caves and rocks, in ravines and chasms.

(Winstedt, 1951: 4)

Menurut Wilkinson (1906: 68), haiwan yang terdapat di rimba semuanya mempunyai peranan dan simbol tersendiri seperti harimau sebagai raja rimba, rusa sebagai putera, pohon kelapa sebagai puteri, pelanduk (chevrotain) sebagai shah alam di rimba. Semua makhluk hutan mempunyai roh atau semangat yang perlu dihormati.

Yahya (2015) menyatakan bahawa proses Indianisasi telah menyebabkan tersebarnya pengaruh kepercayaan Hindu terhadap negeri-negeri di Asia Tenggara. Menurut Yahya, hubungan perdagangan dipercayai berlaku antara India dengan negeri-negeri di Asia Tenggara seawal kurun keempat Sebelum Masihi. Agama seperti Hindu, Buddha dan Islam juga turut menyebarkan kepercayaan alam ghaib (supernatural beings) kepada masyarakat Melayu" (Yahya, 2015: 23). Kenyataan Yahya ini juga dipersetujui oleh Winstedt (1951: 28) yang menyatakan bahawa banyak ritual Hindu masih dipraktiskan oleh orang Islam di alam Melayu. Pendapat Winstedt ini terlihat dalam beberapa upacara masyarakat Melayu lama seperti perkahwinan, mengandung, kelahiran anak dan juga beberapa upacara yang lain. Pernyataan ini bersesuaian dengan pendapat Mohd. Taib (1989: 23): 
Animistic beliefs must have been the core of this religious system. Contemporary Indonesian societies which have remained untouched by foreign influences for the past two thousand years still sucsribe to belief in spirit.

Selain mengembangkan budaya Hindu, tamadun Melayu kuno turut mempercayai makhluk halus. Winstedt (1951) menerangkan:

In Vedic times heaven and earth, rivers and mountains and plats were supplicated as divine powers, and drums and weapons as potent fetishes. As by Malays by the Indians, the Babylonian incantation, Babylonian divination, the Babylonian belief in witchcraft and in evil spirit have been too assimilated for close definition.

(Winstedt, 1951: 27)

Masyarakat Melayu juga mempercayai semangat. Konsep semangat masyarakat Melayu yang dianalisis oleh Endicott (1970) melalui penulisan Cuisinier mendapati roh atau semangat boleh menyerupai pelbagai bentuk serta dapat berpindah dari satu jasad ke satu jasad yang lain. Selain itu, upacara tertentu dilakukan bagi melepaskan semangat, menyambut semangat dan membuat semangat. Semangat dari alam semula jadi dapat mempengaruhi kesihatan seseorang. Menurut Winstedt $(1951,21)$ pula, sesetengah penyakit dipercayai berpunca daripada roh atau semangat yang meresapi badan manusia:

... there are many formless spirits of disease. And as all nature is similarly animated for the Malay, there are spirits of the river-bore, the tall cataract, the jungle track, the forest tree.

Terdapat juga peristiwa dipercayai roh jahat meresapi badan manusia seperti langsuir dari hutan merasuki badan penduduk kampung. Menurut Annandale (1903: 103):

I should, perhaps, explain that the langsuir had no connection with the familiar, being regarded at Grit as a "jungle spirit" (which cannot be tamed) except in so far that all evil spirits are, in the belief of a few of the more intelligent of the Malays, among whom was the headman of Grit, fundamentally one pervading the whole world.

Annandale yang menyaksikan kejadian isteri penghulu kampung dirasuki langsuir turut mengejar isteri penghulu tersebut yang menuju ke sepohon pokok ara. 
Following him we ran through the village, and then, along a narrow jungle path, to the Ficus tree on which the langsuir had declared, in the mouth of the penghulu's wife, that it dwelt. The candle was fixed to its trunk and lighted, and the medicineman called upon "the Seven Sons of the Jinn" (Tujoh Anak Jinn).

(Annandale, 1903: 102)

Mengenai hutan Melayu, orang Melayu sangat menghormati hutan mereka dan dianggap sebagai penceroboh jika menerokai hutan. Berdasarkan pengamatan Maxwell (1982), orang Melayu jarang masuk ke hutan berseorangan walaupun hutan tersebut berdekatan dengan rumah mereka. Mereka mempercayai hutan mempunyai kuasa ghaib seperti jin tanah (the earth spirit), gergasi (giant tusked giants), orang bunyi (the invisible folk), hantu pemburu (spectral hunter) serta makhluk lain yang tidak dapat dilihat oleh mata kasar manusia. Berdasarkan pemerhatiannya lagi, orang Melayu akan memohon kebenaran untuk memasuki hutan seperti yang disaksikan oleh Maxwell sebelum memulakan acara pemburuan. Ketua pasukan menyeru;

Hail! All hail!

We crave permission to enter on this domain

And o tie our nooses to these trees.

(Maxwell, 1982: 9)

Juga dalam konteks menghormati alam, orang Melayu memohon untuk masuk ke dalam hutan tanpa diapa-apakan. Bomoh atau pawang akan menyeru:

I crave pardon for all my errors,

For all shortcomings I crave pardon;

"Peace be with you, Lord of the Forests

(Wilkinson, 1906)

Antara konsep hantu dan roh, orang Melayu mempunyai pendapat yang berbeza. Winstedt (2007) menyatakan, "There is the Spectre Huntsman, known generally as a ghost, in one aspect an avatar of Siva". Terdapat beberapa keramat yang mengaitkan kawasan pergunungan dan hutan seperti Dato' Parol di Gunung Angsi Negeri Sembilan, Penjaga Gunung Berembun Perak, Puteri Gunung Ledang dan Nenek Kemang yang penceritaannya terdapat di Sumatera dan Semenanjung Tanah Melayu. 
Mohd. Taib (1989) menjelaskan bahawa setiap nama menunjukkan kawasan yang dikuasai seperti jembalang tanah (spirit of the earth) atau hantu pemburu (the guardian spirit of the forest and the countryside). Di kawasan hutan dan air (junglewater division), Endicott (1970) yang bersetuju dengan Skeat (1900) menetapkan penguasaan hutan Melayu oleh dewa Hindu seperti Batara Guru yang terletak di balai (state chamber), di gigi rimba (primeval forest) dan di hati rimba ialah 'Toh Panjang Kuku (Grandsire Long-Claws). 'Toh Panjang Kuku ialah dewa yang menghuni jauh di dalam hutan belantara (Endicott, 1970: 102). Dalam konteks bumi dan hutan, Endicott (1970) menyatakan dengan jelas tentang kewujudan hantu raya sebagai great spirit, hantu tanah atau jembalang bumi sebagai earth spirit. Mereka juga dikenali sebagai jin hitam atau jin kafir (black jins atau infidel jins). Hantu raya dilihat sebagai membantu untuk menyembuhkan penyakit seperti hantu belian atau tiger spirit yang digunakan oleh pawang bagi merawat penyakit gangguan daripada makhlus halus (Endicott, 1970: 106).

Makhluk seperti gergasi, jin tanah, orang bunyi dan hantu pemburu dipanggil sebagai hantu hutan (the spirit of the forest) seperti yang dikatakan Maxwell (1982: 8), "the spirits of the forest, and are real to the Malays and as much as dreaded as the rivers and other wild animals of the forest." Sebelum melangkah masuk ke dalam hutan, pemburu akan melafazkan mantera agar tidak tersesat:

As salam aleikom,

Aku datang ini bersahabat sehaja,

Sehaja na' mencari hal khidupan,

Janganlah angkau mengaru-ngaru ku,

Dan anak istri ku,

Dan rumah tangga ku,

Dan segala kampong laman ku,

Aku yang na' tumpang bersahabat ini,

Mintalah selamat pulang balik.

(Maxwell, 1982: 223)

Berdasarkan mantera yang dijampi, memperlihatkan bahawa orang Melayu menghormati makhluk halus di dalam hutan. Setiap baris lebih bersifat apologetik seperti meminta untuk bersahabat dan mohon tidak diganggu makhluk halus hutan semasa berada di dalam hutan. 
Selain itu, orang Melayu juga mempunyai upacara menolak bala seperti yang dijelaskan oleh Pakri (2011) mengenai bomoh yang membakar kemenyan pada malam sebelum acara.

The night before the event begins, Alang Abdullah spends most of his night in burning censers full of resin, and in making small offerings to the Jins of the Water and of the Forest.

(Pakri, 2011: 66)

Di Perak dan beberapa hutan di negeri lain, terdapat makhluk yang dinamakan orang bunyi. Orang bunyi dikatakan tidak berbahaya malah turut membantu orang yang sesat dalam hutan. Swettenham (1899: 186) memberikan deskripsi mengenai Orang Bunyi.

This superstition is of ancient origin, and the "sound folk" are supposed to frequent certain secluded places, usually streams or swamps in the heart of jungle, where they are heard, by wood-cutters and other venturesome people, paddling their phantom boats through the water, talking singing, but very rarely, if ever disclosing themselves to mortals.

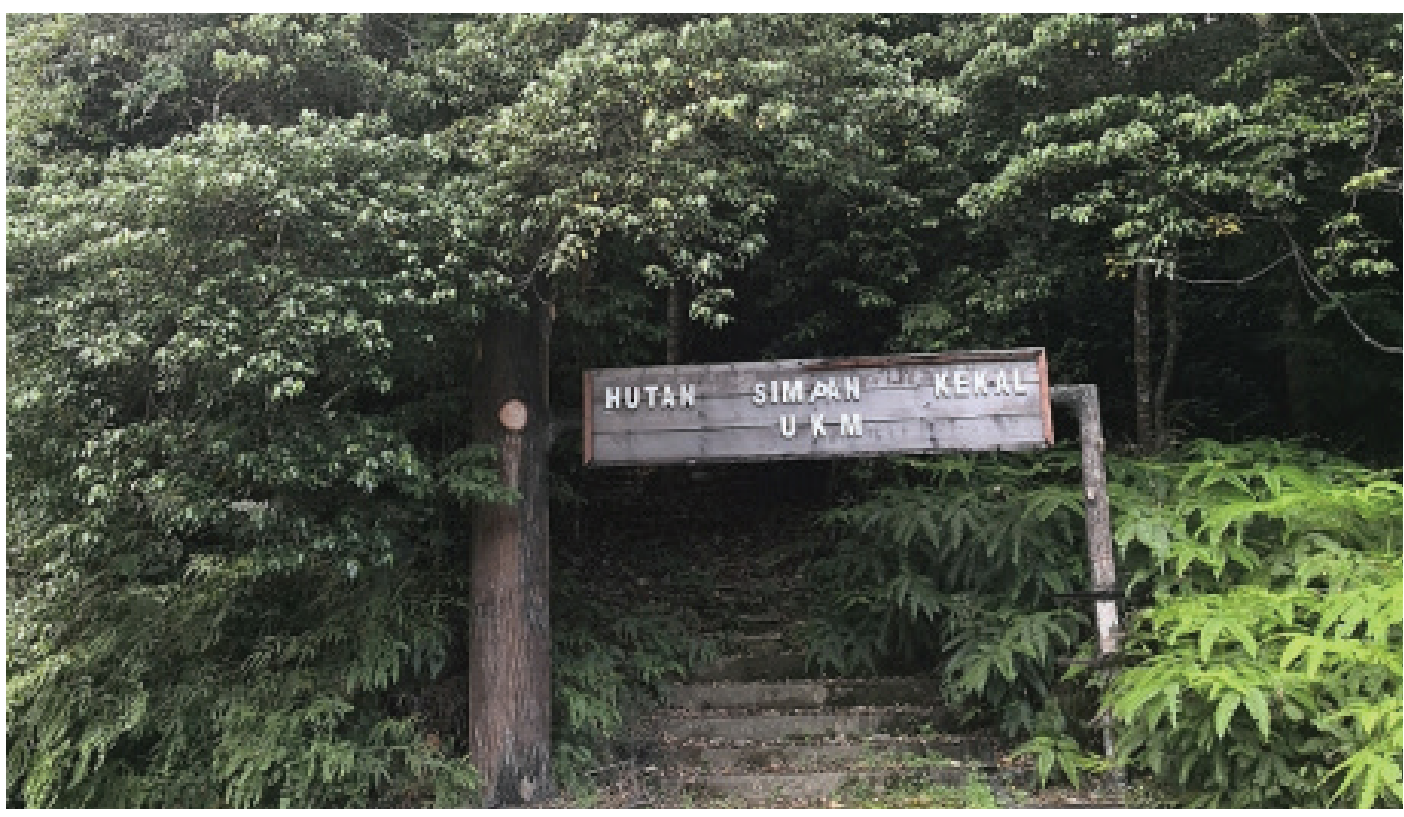

Rajah 3 Hutan simpan kekal yang terletak di kawasan Universiti Kebangsaan Malaysia. 
Tersesat di dalam hutan Melayu menjadi satu perkara yang perlu dihindari oleh setiap peneroka hutan. Swettenham (2016: 75) mengingatkan individu yang memasuki hutan agar tidak tersesat dan hilang:

I have elsewhere tried to describe a Malay jungle, and the path which these men had to traverse was, as I know from my own experience, beset with peculiar difficulty, and led for a great deal of the way through swamp and water, where, of course there was no track visible. It is not surprising that the party lost its way.

Terdapat juga keadaan semasa peneroka hutan yang sesat cuba mencari jalan pulang menemui kegagalan dan dalam keadaan yang lapar dan terdesak, mereka terus meredah hutan belantara dan tidak ditemui oleh sesiapapun sehingga ke akhirnya (Swettenham, 2016: 75).

\section{KESIMPULAN}

Melalui naratif gambaran hutan Melayu oleh penulis zaman kolonial yang kebanyakannya terdiri daripada pegawai tinggi British seperti Maxwell, Clifford, Swettenham, Fauconnier, Endicott, Winstedt, Skeat, Wilkinson serta Annandale berjaya merungkaikan pandangan semesta orang Melayu terhadap hutan secara fizikal dan spiritual. Tidak dinafikan keindahan hutan Melayu yang mempersonakan dirasai segelintir pegawai British seperti Maxwell, namun tidak kurang juga beranggapan hutan Melayu menjengkelkan seperti yang dinukilkan oleh Swettenham. Keseluruhan catatan pegawai kolonial British ini menggambarkan bahawa hutan Melayu merupakan suatu misteri dan menarik untuk diterokai. Pada pandangan pegawai Barat, peristiwa aneh, fenomena metafizikal serta amalan spiritual yang dialami oleh peneroka hutan sukar diinterpretasikan dengan kelogikan akal fikiran namun menjadi lumrah sebermulanya penapakan tamadun Melayu di Nusantara. Sifat fizikal dan kemistikan spiritual hutan Melayu bukan sahaja menjadi wahana penyampaian budaya dan legasi masyarakat Melayu terdahulu malahan secara tidak langsung memelihara dan memulihara khazanah alam tamadun Melayu.

Kebergantungan masyarakat Melayu terhadap alam semula jadi dapat diterjemahkan melalui interpretasi pengalaman penerokaan hutan yang bukan sahaja menjana ekonomi dan menyara diri mereka malahan memenuhi aspek kerohanian seperti kepercayaan terhadap alam ghaib. Peranan hutan secara tidak langsung membentuk jati diri bangsa dan peradaban Melayu yang tidak meletakkan kebergantungan hidup kepada penjanaan industri dan permodenan. Keadaan ini berlainan dengan cara hidup kebanyakan pegawai kolonial British yang terbiasa 
dengan kehidupan kota dengan masyarakat pertanian di alam Melayu. Melalui pengamatan dan pengalaman mereka yang terpaksa meredah hutan belantara dengan jiwa yang kental bersama-sama dengan orang Melayu merobah persepsi mereka mengenai hutan. Berdasarkan analisis autoetnografi hutan Melayu melalui naratif penulis zaman kolonial, dapatlah disimpulkan bahawa hutan Melayu menghasilkan kebudayaan berbentuk fizikal dan spiritual melalui kebergantungan masyarakat alam Melayu terhadap alam rimba.

\section{RUJUKAN}

Annandale, N. (1903). A magical ceremony for the cure of a sick person among the Malays of upper Perak. Man 3: 100-103. doi: 10.2307/2840511.

Cameron, J. (1865). Our tropical possessions in Malayan India - Being a descriptive account of Singapore, Penang, Province Wellesley, and Malacca: Their peoples, products, commerce, and government. London: Smith, Elder \& Co.

Clifford, H. C. (1989). In court and kampung. Singapura: Graham Brash.

Douglas, K. \& Carless, D. (2013). A history of autoethnographic inquiry, 84-106. Dalam S. H. Jones, T. E. Adams, and C. Ellis (Eds.), Handbook of autoethnography. Abingdon: Routledge. Diakses daripada https://www.routledgehandbooks.com/ doi/10.4324/9781315427812.ch2 pada 7 Mei 2020.

Endicott, K. M. (1970). An analysis of Malay magic. London: Oxford University Press.

Fauconnier, H. (1990). The soul of Malaya (Trans. E. Sutton). Singapura: Oxford University Press.

Fuad Hassan. (2018). Berkenalan dengan eksistensialisme. Jakarta: PT Dunia Pustaka Jaya. Grimal, P. (1965). Larousse world mythology. UK: Paul Hamlyn Limited.

Jones, S. H. (2005). Autoethnography: Making the personal political, 763-792. Dalam N. K. Denzin and Y. S. Lincoln (Eds.), The sage handbook of qualitative research. Thousand Oaks: Sage Publications Ltd.

Kaur, A. \& Metcalfe, I. (1999). The shaping of Malaysia. UK: Palgrave Macmillan.

Maxwell, G. (1907). In Malay Forests. Edinburgh and London: William Blackwood and Sons.

Maxwell, G. (1982). In Malay forests. Selangor: Eastern Universities Press Sdn. Bhd.

Mohd. Taib Osman. (1989). Malay folk beliefs: An integration of disparate elements. Kuala Lumpur: Dewan Bahasa dan Pustaka.

Nigh, R. B. \& Nations, J. D. (1980). Tropical rainforests. Journal Bulletin of the Atomic Scientists 36(3): 12-19. doi: 10.1080/00963402.1980.11458703.

Pakri, M. R. (2011). An imperial or a personal legacy? The rivalry of W. E. Maxwell and F. A. Swettenham in British Malaya. Journal of the Malaysian Branch of the Royal Asiatic Society, 84(2 (301)), 33-44. 
Pusat Rujukan Persuratan Melayu. n.d. Keramat. Kamus Pelajar Edisi Kedua (Pusat Rujukan Persuratan Melayu). Diakses daripada http://prpm.dbp.gov.my/ Cari1?keyword=keramat\&d=176312\& pada 2017 .

Puteh Noraihan A. Rahman. (2018). Simbolisme dewa-raja dalam teks Melayu Klasikterpilih dan kesannya terhadap adat istiadat Kesultanan Melayu (Tesis PhD diterbitkan). Kuala Lumpur: Universiti Malaya.

Roberts, G. (2006). History, theory, and the narrative turn in IR. Review of International Studies, 32(4): 703-714. doi: 10.1017/S0260210506007248

Skeat, W. W. (1900). Malay Magic: Being an introduction to the folklore and popular religion of the Malay Peninsula. London: Macmillan.

Swettenham, F. (1887). On the native races of the Straits settlements and Malay states. The Journal of the Anthropological Institute of Great Britain and Ireland, 16, 221-229. doi: $10.2307 / 2841811$

Swettenham, F. (1899). The real Malay: Pen pictures. London: John Lane The Bodley Head.

Swettenham, F. (2003). Perihal orang Melayu (Trans. Zubaidah Ibrahim). Kuala Lumpur: UM Press.

Swettenham, F. (2016). Malay sketches (Annotated edition). Kuala Lumpur: Silverfish Books.

Tamura, E. H. (2011). Narrative history and theory. History of Education Quarterly, 51(2): 150-157. doi: 10.1111/j.1748-5959.2011.00327.x.

Wilkinson, R. J. (1906). The Peninsular Malays - I. Malay beliefs. London: Luzac and Co.

Winstedt, R. O. (1951). The Malay magician: Being shaman, saiva and sufi. London: Routledge and Paul.

Winstedt, R. O. (2007). Shaman, saiva and sufi: A study of the evolution of Malay magic. Charleston, South Carolina: Bibliobazaar.

World Wide Fund for Nature (WWF). n.d. Forests. WWF - Malaysia. Diakses daripada http://www.wwf.org.my/about_wwf/what_we_do/forests_main/(pada 12 Sept 2019).

Yahya, F. (2015). Magic and divination in Malay illustrated manuscripts. London: Brill.

Tarikh Peroleh (received): 16 Julai 2020

Tarikh Terima (accepted): 21 Disember 2020 